\title{
High strength bimetallic composite material fabricated by electroslag casting and characteristics of its composite interface
}

\author{
*Tian-shun Dong, Jin-hai Liu, Qian Fang, Guo-lu Li and Jian-jun Zhang \\ School of Material Science and Engineering, Hebei University of Technology, Tianjin 300130, China
}

\begin{abstract}
Bimetallic composite material of bainitic steel and PD3 steel was produced with electroslag casting process, and element distribution of its composite interface was investigated by theoretical calculation and energy dispersive spectrometer (EDS). Results show that the tensile strength (1,450 MPa), hardness (HRC 41-47) and impact toughness $\left(94.7 \mathrm{~J} \cdot \mathrm{cm}^{-2}\right)$ of bainitic steel were comparatively high, while its elongation was slightly low $(4.0 \%)$. Tensile strength $(1,100 \mathrm{MPa})$, hardness $(>\mathrm{HRC} 31)$ and elongation $(7.72 \%)$ of the interface were also relatively high, but its impact toughness was low at $20.4 \mathrm{~J} \cdot \mathrm{cm}^{-2}$. Results of theoretical calculation of the element distribution in the interface region were basically consistent with that of EDS. Therefore, electroslag casting is a practical process to produce bimetallic composite material of bainitic steel and PD3 steel, and theoretical calculation also is a feasible method to study element distribution of their interface.
\end{abstract}

Key words: electroslag casting; bimetallic composite material; bainitic steel; interface

CLC numbers: TG142.33/142.72Ｄocument code: A Article ID: 1672-6421(2016)06-389-07

$\mathrm{I}$

n recent years, with the continuous development of the train industry all over the world towards high speed and heavy load, it puts forward accordingly higher requirements for the properties of railway crossings. In spite of high manganese steel being widely used in railway crossings, bainitic steel provides a good alternative due to its high strength, high toughness, suitable hardness, good abrasive resistance, good weldability and long life span, etc ${ }^{[1-4]}$. Nowadays, bainitic crossings are normally made of two parts: bainitic steel core rail and PD3 steel wing rails, as shown in Fig. $1^{[5-7]}$. However, such crossings are mostly connected in the form of a mechanical combination, which has many shortcomings in entirety, stability, smooth running of trains, installation and maintenance. Therefore, it is necessary to develop an integrated crossing with bainitic steel and PD3 steel. Some researchers have studied flash butt welding of bainitic steel rail and carbon steel rail ${ }^{[8]}$, but both these two kinds of steel have high cracking sensitivity to

\section{*Tian-shun Dong}

Male, born in 1968, Associate Professor. His research interests mainly focus on material forming technology.

E-mail: dongtianshun111@163.com

Corresponding author: Jin-hai Liu, email: jhliu57@hebut.edu.cn

Received: 2016-05-04; Accepted: 2016-10-08

welding, which restricts the promotion and application of flash butt welding process of bainitic steel and PD3 steel.

The electroslag casting process has been widely applied to produce many important castings used in machinery, transportation and chemical engineering, etc. Due to the refining effect of electroslag casting,

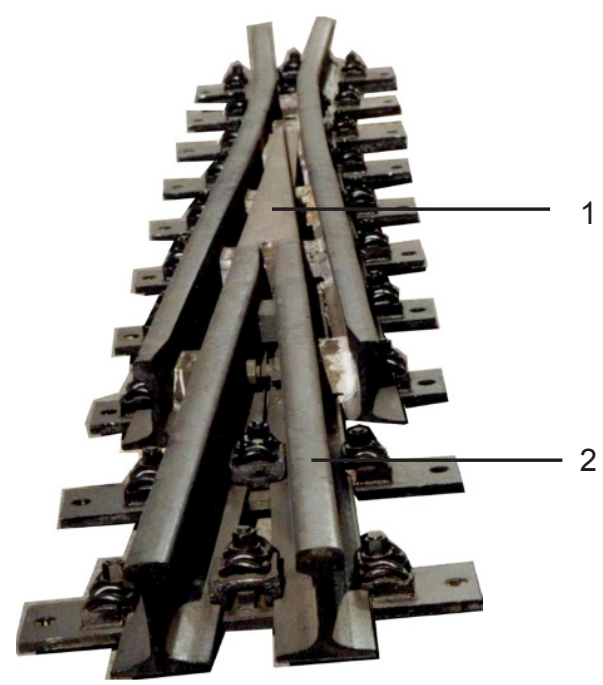

1. Bainitic steel core rail, 2. PD3 steel wing rail

Fig. 1: Actual figure of bimetallic crossing 
non-metallic inclusions and harmful elements in steel are effectively eliminated and some defects such as porosity and segregation are effectively avoided ${ }^{[9]}$. Till now, however, no detailed investigation has been conducted regarding developing a bimetallic composite crossing with the electroslag casting process.

In this study, a bimetallic composite material was produced with the electroslag casting process. Subsequently, microstructure and mechanical properties of its composite interface were studied. The work of this paper has some potential in developing a bimetallic composite crossing of bainitic steel and PD3 steel.

\section{Experimental procedure}

A bainitic steel consumable electrode was prepared in advance by metal mold casting process, and a section was cut from a commercial PD3 rail steel, both of their surfaces were cleaned. Subsequently, electroslag casting was carried out with the bainitic steel consumable electrode being placed above the PD3 steel rail vertically. Solid slag arc striking method was used. With the molten droplets from the bainitic steel consumable electrode constantly dripping on the top of the PD3 steel, the bainitic steel molten liquid solidified and combined together with the PD3 steel rail. Chemical compositions of these two steels are shown in Table 1. The current used for electroslag casting was 2000-2500 A, the voltage was $40 \mathrm{~V}$. $\mathrm{CaF}_{2}-\mathrm{Al}_{2} \mathrm{O}_{3}$ binary slag system was used with a ratio of $70 \% \mathrm{CaF}_{2}$ and $30 \%$ $\mathrm{Al}_{2} \mathrm{O}_{3}$.

After electroslag casting, the bimetallic composite material was heat treated according to the following specifications: austenitized at $920^{\circ} \mathrm{C}$ for $45 \mathrm{~min}$, then cooled in air to about $300{ }^{\circ} \mathrm{C}$, and slowly cooled in the furnace for $8 \mathrm{~h}$. A section was intercepted from the integral bimetallic composite material after heat treatment, including bainitic steel, PD3 steel and the composite layer, as shown in Fig. 2.

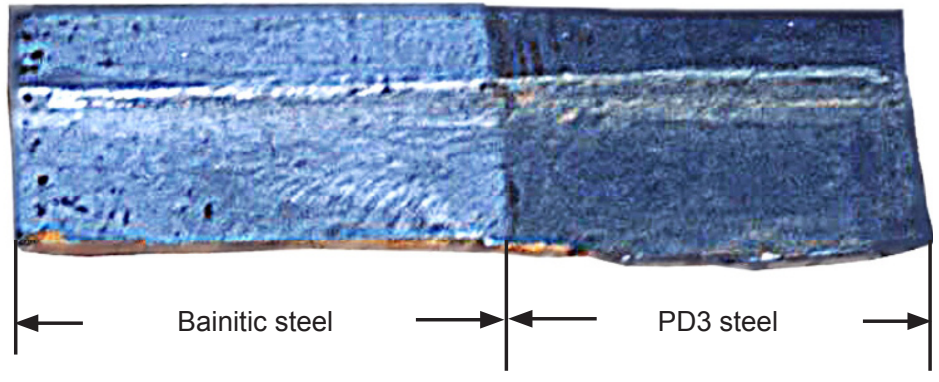

Fig. 2: A section intercepted from bimetallic composite material

Table 1: Chemical compositions of bainitic steel and PD3 steel (wt.\%)

$\begin{array}{cccccccccr} & \mathbf{C} & \text { Si } & \text { Mn } & \text { P } & \text { S } & \text { Cr } & \text { Mo } & \text { Ni } & \text { V } \\ \text { Bainitic steel } & 0.28 & 0.89 & 1.96 & 0.017 & 0.0040 & 0.93 & 0.33 & 0.82 \\ \text { PD3 steel } & 0.70 & 0.59 & 0.95 & 0.015 & - & - & - & - & 0.10-0.20\end{array}$

Samples were taken respectively from three zones at bainitic steel, PD3 steel and the composite layer using wire cutting, and then machined into tensile test bars and impact specimens (with U-notch). Tensile testing was carried out on a SHT5305 microcomputer controlled electro-hydraulic servo universal testing machine. Impact toughness was tested with a jb$150 / 300$ type pendulum impact testing machine. The fracture and microstructure was observed with a Philips XL30 scanning electron microscope. Hardness distribution of the composite layer was detected with a HR-150A type Rockwell hardness tester and a HMV-2T microhardness tester.

\section{Results and discussion}

\subsection{Microstructure of the composite interface}

Figure 3 shows the microstructure of the interface region of bainitic steel and PD3 steel. As a kind of high-carbon steel, PD3 has poor hardenability because of the little alloy elements content. A thermal expansion test of PD3 steel showed that, if held at $920{ }^{\circ} \mathrm{C}$ for $10 \mathrm{~min}$ and cooled at a speed of $30{ }^{\circ} \mathrm{C} \cdot \mathrm{min}^{-1}$, pearlite transformation took place at $645^{\circ} \mathrm{C}$ and ended at 618 ${ }^{\circ} \mathrm{C}$ with all undercooled austenite transformed. Therefore, under the condition of this present experiment, the structure of PD3 steel transformed into fine pearlite, while the structure of the core rail material gained in electroslag casting is fine acicular bainite accompanied by some retained austenite films. Coastline boundary exists between bainitic steel and PD3 steel.

What should be noted is that the actual melting line undulated around the theoretical melting line (as shown in Fig. 4) under practical electroslag casting conditions, and the reasons are as follows:

(1) Molten droplets from the consumable electrode continuously dripped onto the surface of PD3 steel during the process of electroslag casting, transmitting heat to PD3 steel simultaneously. Due to the irregularity of the droplet transfer, the heat input into the surface of PD3 was not uniform.

(2) From the micro-perspective, the surface and the structure of PD3 steel was not even, so the heat dissipation condition of each point on the surface of PD3 steel was not consistent.

(3) Inhomogeneity of local chemical composition of PD3 steel would also change the local melting temperature, thus resulting 

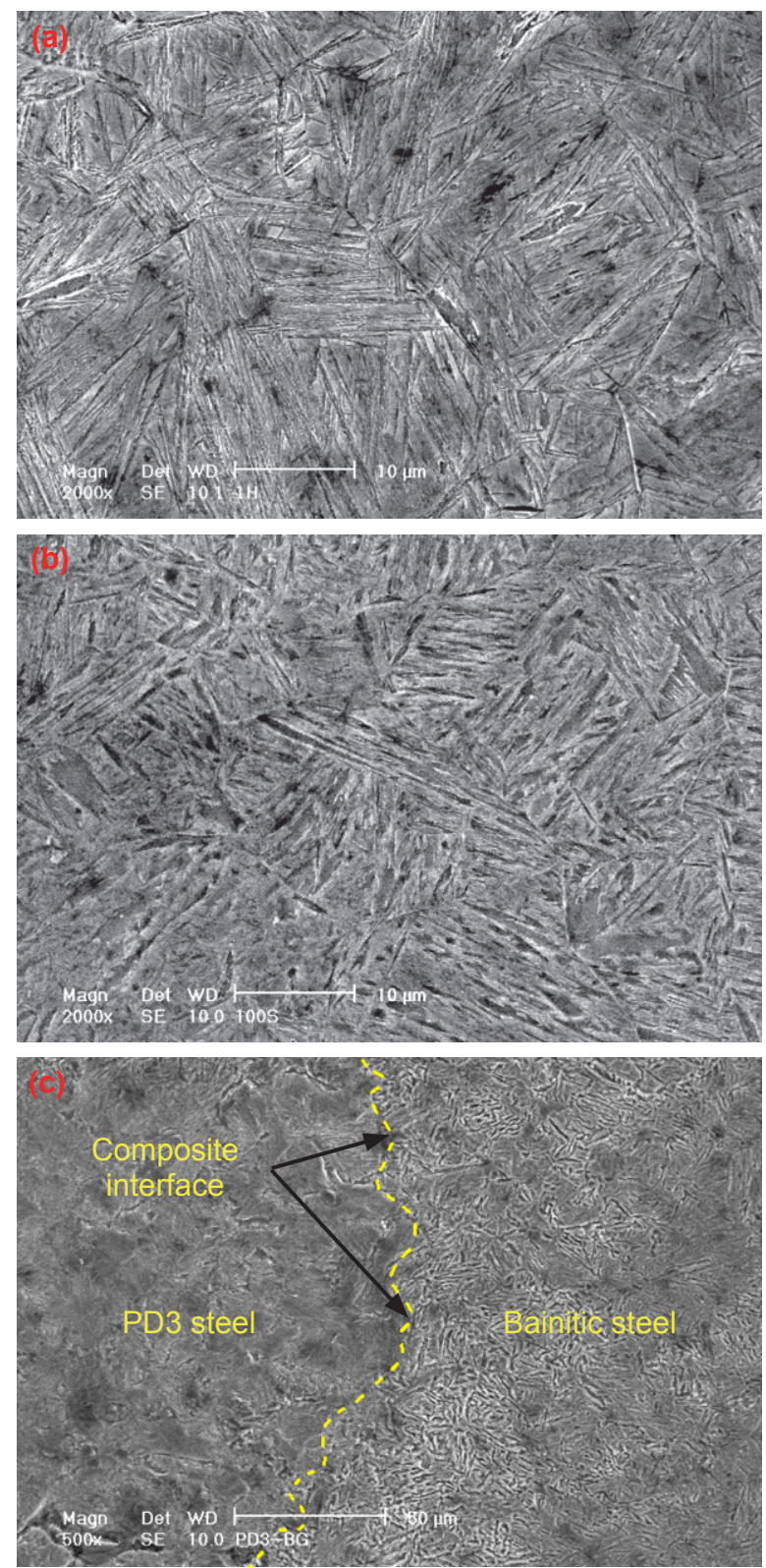

Fig. 3: Microstructures of PD3 steel (a), bainitic steel (b) and composite interface (c)

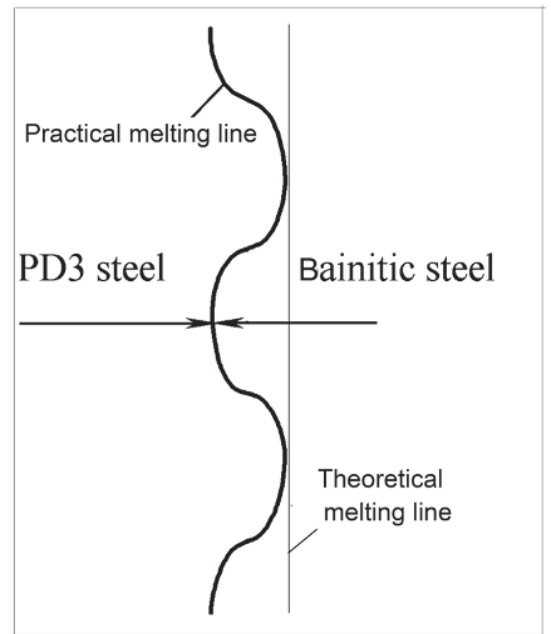

Fig. 4: Schematic diagram of PD3 steel and bainitic steel interface in uneven melting of its surface.

Therefore, a coastline interface formed between PD3 steel and bainitic steel, which is helpful to improve the binding strength of their interface.

\subsection{Mechanical properties of the composite interface}

\subsubsection{Hardness and microhardness}

The average Rockwell hardness obtained along five different routes at the interface is shown in Fig. 5. The microhardness at the interface is shown in Fig. 6. It can be seen from Fig. 5 that Rockwell hardness of bainitic steel is relatively high, at about HRC43-45. Although the Rockwell hardness of the heat treated PD3 steel is slightly low, its lowest hardness of HRC35 is still higher than that of as cast PD3 steel (HRC1923). The Rockwell hardness value of the interface is between bainite steel and PD3 steel. In particular, in the nearest neighbor region of the interface, a peak value of hardness emerged in the bainitic steel side, and this phenomenon is more obvious in Fig. 6 , the reason being that the bainite obtained at the beginning of electroslag casting was relatively fine due to rapid cooling. Meanwhile, a valley value of hardness appeared in the PD3 steel side about $1 \mathrm{~mm}$ away from the interface, forming a softening area. This is because overheating in the electroslag casting led to

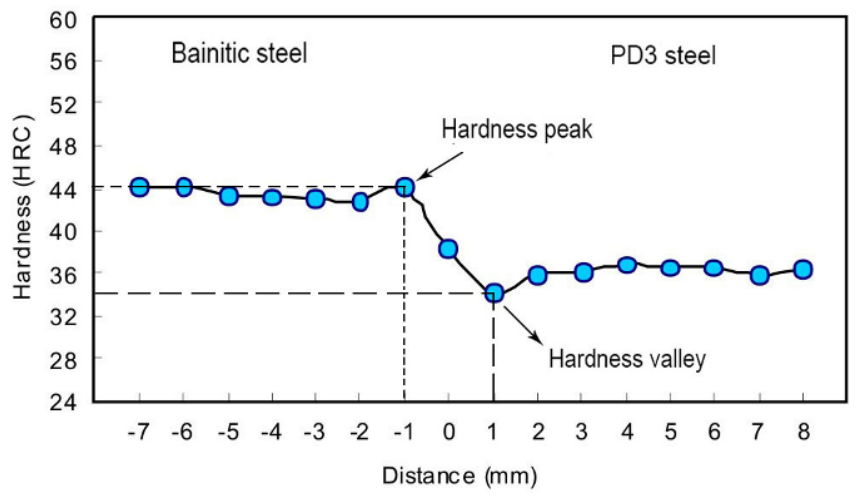

Fig. 5: Schematic diagram of PD3 steel and bainitic steel interface

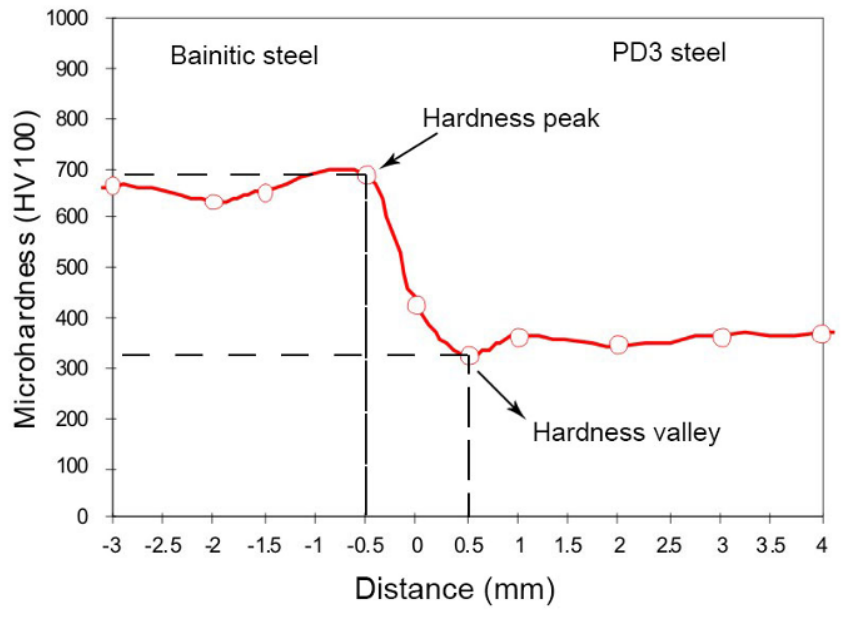

Fig. 6: Microhardness distribution at the interface 
grain coarsening in this region. But, since the softening zone is very narrow and between two adjacent strong bodies, it will be constrained by the adjacent strong body and give rise to strainstrengthening when bearing deformation. So the strength loss of the interface can be compensated to some extent, leading to the test bar not fracturing in this place during the tensile test (shown in Fig.7). It can be seen from Fig.6 that the distribution rule of microhardness at the composite interface is basically consistent with that of Rockwell hardness as shown in Fig. 5.

\subsubsection{Tensile properties and impact toughness}

Figure 7 shows the fracture location of tensile test bar with composite interface in the center region. It is evident that the fracture appeared in PD3 steel rather than at composite interface. Table 2 shows the mechanical properties of different positions. It can be seen that PD3 steel has exhibited good mechanical properties. Meanwhile, the tensile strength 1,450 $\mathrm{MPa}$ and the impact toughness $94.7 \mathrm{~J} \cdot \mathrm{cm}^{-2}$ of bainitic steel are excellent, but its elongation $4 \%$ is slightly low. Although the railway standards of China have not proposed clear requirements on elongation

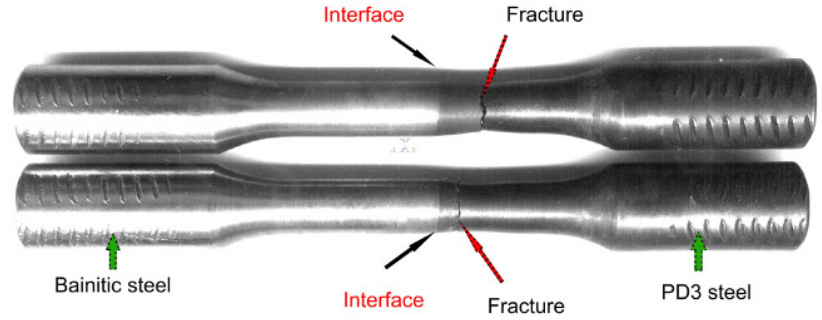

Fig. 7: Fracture location of interface tensile test bar

of the crossing ${ }^{[10]}$, some effective measures must be taken for further improvement in order to ensure the safety of railway transportation. The interface has a relatively high tensile strength $(1,100 \mathrm{MPa})$, but owing to some casting defects existing in some impact specimens, its impact toughness is only $20.4 \mathrm{~J} \cdot \mathrm{cm}^{-2}$ on average. Although the impact toughness value of the interface is not high, it is higher than that produced with flash butt welding process as established by Li et al ${ }^{[11]}$.

Table 2: Mechanical properties of bainitic steel, PD3 steel and composite interface

\begin{tabular}{|c|c|c|c|c|c|}
\hline & \multirow{2}{*}{$\begin{array}{c}\text { Standard } 165(2005) \text { of } \\
\text { Ministry of Railways } \\
\text { (China) }{ }^{[10]}\end{array}$} & \multirow[b]{2}{*}{ Bainitic steel } & \multicolumn{2}{|c|}{ PD3 steel } & \multirow[b]{2}{*}{ Composite interface } \\
\hline & & & Rail head & Rail waist & \\
\hline Tensile strength (MPa) & $\geqslant 1240$ & 1450 & 943 & 838 & 1100 \\
\hline Elongation (\%) & - & 4.0 & 10.0 & 18.0 & 7.7 \\
\hline Impact toughness $\left(\mathrm{J} \cdot \mathrm{cm}^{-2}\right)$ & $\geqslant 70$ & 94.7 & 36.3 & 39.9 & 20.4 \\
\hline
\end{tabular}

\subsection{Impact fracture}

Figure 8 shows SEM morphology of impact fracture of bimetallic composite material. It can be seen from Fig. 8(a) that a large number of dimples exist on the fracture of bainitic steel, which is characteristic of typical ductile fractures, while clear river patterns on the impact fractures of PD3 steel specimens exhibited characteristics of typical cleavage fracture, as shown in Fig. 8(b). Although there are some obvious river patterns on the fracture of the interface in Fig. 8(c) and consequently exhibited cleavage fracture characteristics too, compared with Fig. 8(b), the river patterns are a little shorter, the cleavage planes are slightly smaller, and some dimples and tearing edges existed in the red circle area of Fig. 8(c). Therefore, the fracture of interface showed some characteristics of quasi-cleavage fracture.

For the bainitic steel obtained in this research, its excellent impact toughness resulted not only from fine bainite and the existence of residual austenite film, but also from the refining role of electroslag casting which effectively eliminated defects such as non-metallic inclusions and porosity.

As for the interface, although the impact fracture morphology of the interface is not worse than that of PD3 steel, its impact toughness is still lower than that of PD3 steel evidently. The reason is that the cooling rate of molten droplets at the beginning of electroslag casting is fast, so it isn't easy for gas or slag in the melt to escape, which readily causes porosity, slag inclusion and significantly weakens the impact toughness of the interface. Morphology and EDS analysis of slag inclusion at the composite interface are shown in Fig. 9. In addition, since the heat expansion coefficient, yield strength and elastic modulus of both sides of the interface are different, stress concentration will rise during the process of cooling in electroslag casting. Moreover, the heterogeneity of composition and structure distribution can aggravate the degree of stress concentration of the interface, so its impact toughness is reduced. In future electroslag casting, further measures must be taken to eliminate defects and improve the impact toughness of the interface effectively.

\subsection{Element distribution at the interface}

Due to the existence of concentration gradient in the distribution of chemical elements in adjacent areas of the interface between bainite steel and PD3 steel, a solid diffusion phenomenon of chemical element would take place during the electroslag 

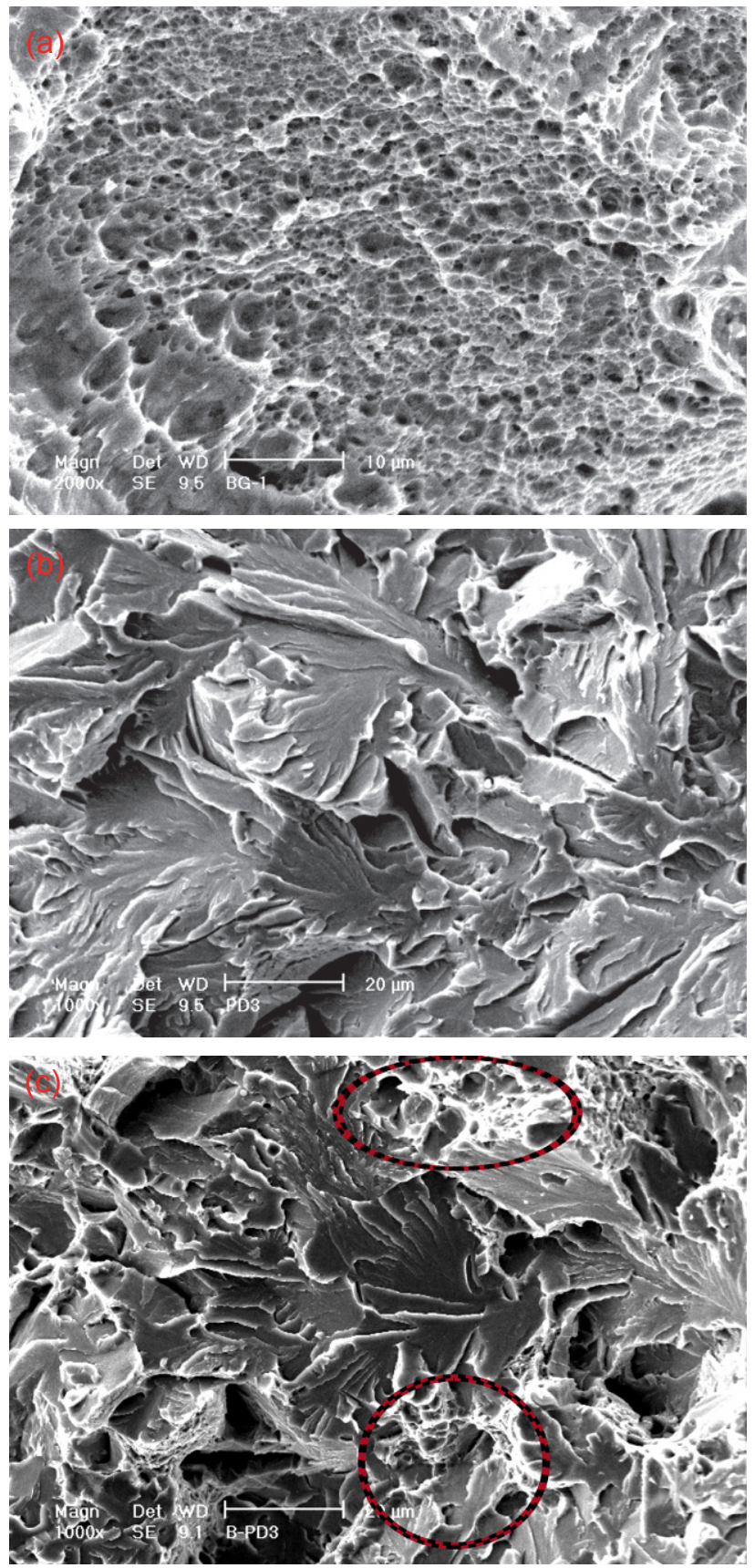

Fig. 8: Impact fracture morphologies of bainite steel
(a), PD3 steel (b), and composite interface (c)

casting process and the subsequent heat treatment, which will affect the microstructure and mechanical properties of the interface. Therefore, the element distribution in the interface area was analyzed both by theoretical calculation and by EDS in this research.

To facilitate the mathematical calculation, the composite interface was imagined as a diffusion couple composed of two materials extending to positive infinity and negative infinity respectively, as shown in Fig.10.

According to Fick's Second Law applicable to unsteady diffusion:

$$
\frac{\partial c}{\partial t}=D \frac{\partial^{2} c}{\partial^{2} x}
$$

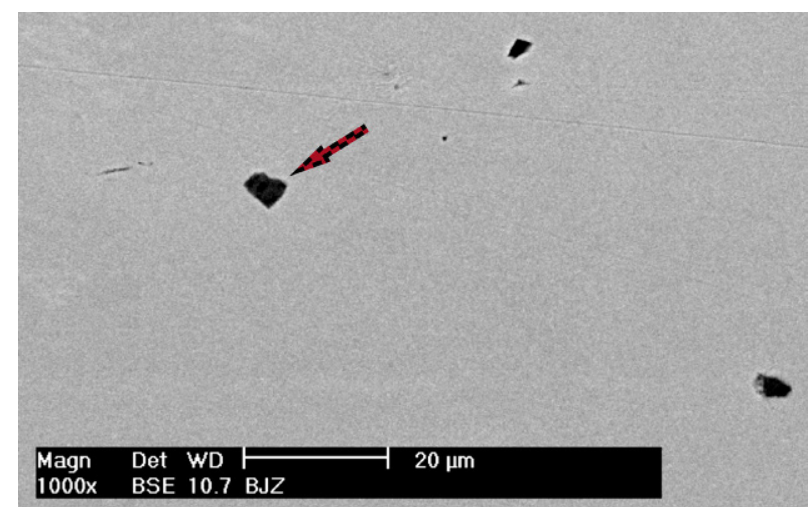

\begin{tabular}{|c|c|c|}
\hline Element & wt. $\%$ & at. $\%$ \\
\hline NK & 15.49 & 38.55 \\
\hline AlK & 1.39 & 1.79 \\
\hline TiK & 75.13 & 54.67 \\
\hline FeK & 7.99 & 4.98 \\
\hline Total & 100.00 & 100.00 \\
\hline
\end{tabular}

Fig. 9: Morphology and EDS analysis of slag inclusion at composite interface

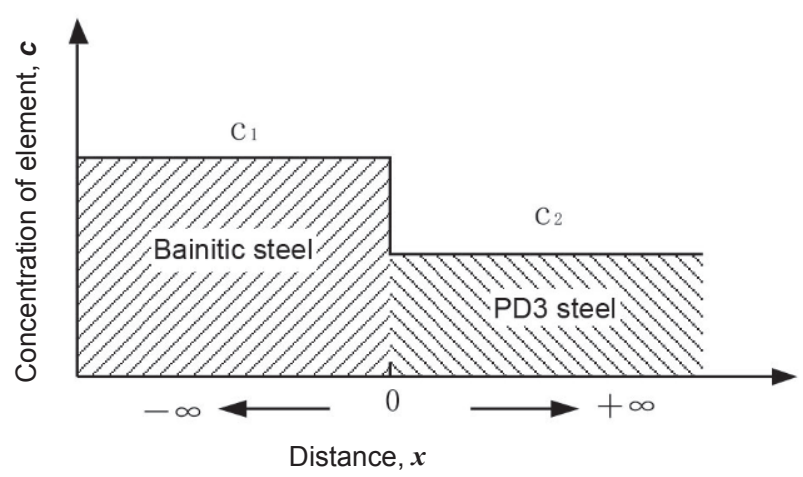

Fig. 10: Schematic diagram of diffusion couple

The chemical element distribution in the interface region could be expressed as follows:

$$
\frac{c-c_{2}}{c_{1}-c_{2}}=\frac{1}{2}\left[1-\operatorname{erf}\left(\frac{x}{2 \sqrt{D t}}\right)\right]
$$

where $t$ is time, $c$ is an element's concentration of different time and different distance, $c_{1}$ is concentration of the element in bainite steel when $t=0, c_{2}$ is concentration of the element in PD3 steel when $t=0, D$ is the element's diffusion coefficient in austenite, which is regarded as a constant for simplicity in this study, $x$ is the distance away from the interface. 
When the above equation is used to calculate the distribution of alloying elements in steel, it is essential to determine the element's diffusion coefficient $D$ in austenite. According to the Arrhenius formula:

$$
D=D_{0} \exp (-Q / R T)
$$

where $D_{0}$ is frequency factor, $R$ is gas constant $8.314 \mathrm{~J} \cdot(\mathrm{mol} \cdot \mathrm{K})^{-1}$, $T$ is temperature, $Q$ is diffusion activation energy which can be estimated in the following equation:

$$
Q=R T_{M}\left(K_{0}+V\right)
$$

where $T_{\mathrm{M}}$ is thermodynamic melting point, $V$ is the atomic weight of the metal, $K_{0}$ is a parameter only related to crystal structure and is 17 for face-centered cubic structure, $R$ is gas constant $8.314 \mathrm{~J} \cdot(\mathrm{mol} \cdot \mathrm{K})^{-1} . D_{0}$ and $Q$ values (approximation) of some alloy diffusion systems are shown in Table $3^{[12]}$.

The theoretical distribution of some elements in the composite interface region, such as $\mathrm{C}, \mathrm{Mn}, \mathrm{Si}, \mathrm{Ni}$, etc, can be calculated according to Equations 1 through 4 and Table 3. For example, when $T=1,473 \mathrm{~K}$, theoretical distribution of $\mathrm{C}$ can be obtained, as shown in Fig. 11. It can be seen that $\mathrm{C}$ has diffused gradually from the PD3 into bainitic steel, and with time prolonging, theoretical distribution of $\mathrm{C}$ is more and more close to actual EDS result. Diffusion occurs within the range of approximately $3 \mathrm{~mm}$ in both sides of the interface.

It should be mentioned that the theoretical calculation above is based on a solid-solid diffusion couple. But in fact, at the beginning of electroslag casting, droplets from bainitic steel made PD3 steel partially melt when they reached the surface of the latter, and formed a transiently liquid-solid diffusion couple before solidification. In addition, the temperature and time used in the theoretical calculation were different from the actual ones, and some parameters were simplified. Therefore, the results of theoretical calculation differ from those of actual calculations. In spite of this, the results of the theoretical calculation are roughly consistent with that of EDS analysis.

\section{Conclusions}

(1) The bimetallic composite material made up of bainitic steel and PD3 steel was produced by electroslag casting process, with the structure of needle bainite and a small amount of residual austenite film in bainitic steel. A coastline interface formed between bainitic steel and PD3 steel.

(2) The tensile strength of bainitic steel, PD3 steel and the interface of the bimetallic composite material are all relatively high, but the elongation of bainitic steel and the impact toughness of the interface were comparatively low. Therefore, electroslag casting is a practical process to produce bimetallic composite material of bainitic steel and PD3 steel, but it is necessary to improve the process and further decrease casting defects.

(3) For the element distribution in the interface region, the results of theoretical calculations basically corresponded with
Table 3: $D_{0}$ and $Q$ values in some alloy diffusion system (approx.)

$\begin{array}{cccc}\text { Diffusion component } & \text { Matrix } & \boldsymbol{D}_{0}\left(\mathbf{1 0}^{-5} \mathrm{~m}^{2} \cdot \mathrm{s}^{-1}\right) & \boldsymbol{Q}\left(10^{3} \mathrm{~J} \cdot \mathrm{mol}^{-1}\right) \\ \mathrm{C} & \mathrm{V}-\mathrm{Fe} & 2.0 & 140.0 \\ \mathrm{Ni} & \mathrm{V}-\mathrm{Fe} & 4.4 & 283.0 \\ \mathrm{Mn} & \mathrm{V}-\mathrm{Fe} & 5.7 & 277.0 \\ \mathrm{Si} & \mathrm{V}-\mathrm{Fe} & 0.1 & 345.7\end{array}$

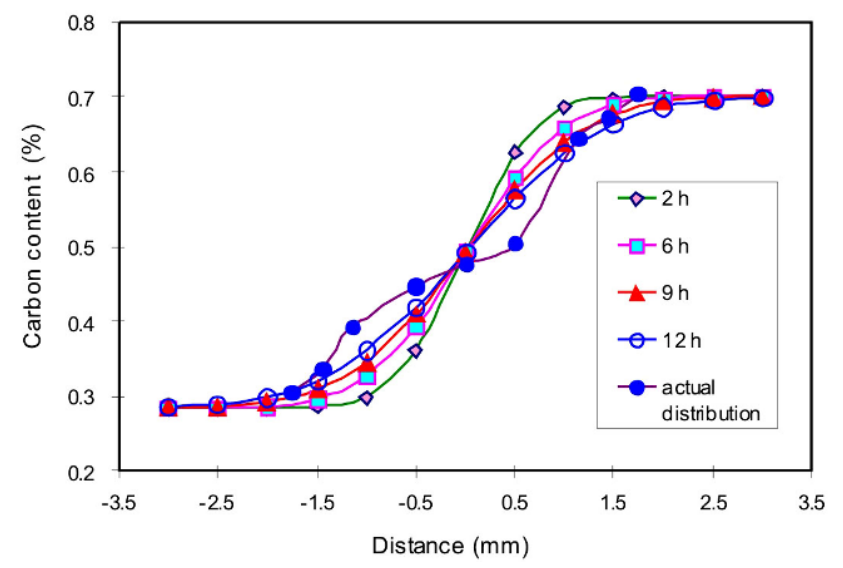

Fig. 11: Comparison of theoretical and actual distribution of carbon element at the interface

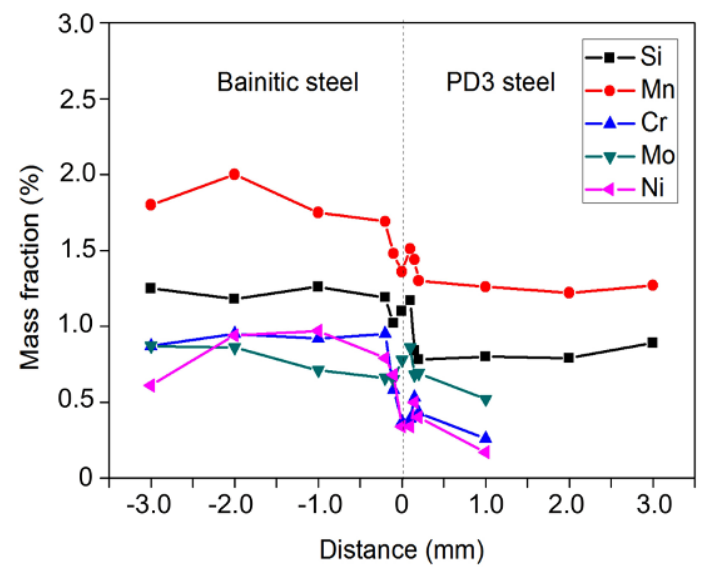

Fig. 12: Result of EDS analysis of the interface composition

the results of EDS analysis, hence theoretical calculation is a feasible method to study element distribution of the composite interface of electroslag casting.

\section{References}

[1] Frank E E. Evolution of the rail-bound manganese frog. Transportation Research Record, 1986,1071: 43-48.

[2] Zhang F C, Lü B, Hu B T, et al. Flash butt welding of high 
manganese steel crossing and carbon steel rail. Materials Science and Engineering A, 2007, 454-455: 288-292.

[3] Davis D, Scholl M, Sehitoglu H. Development of bainitic frogs for HAL service. Railway Track \& Structures, 1997, 35(12): 1416.

[4] Zheng C L, Bo L, Zhang F C, et al. Heat treatment and application of W-Al-containing bainitic steel used for crossing. Transactions of Materials and Heat Treatment, 2009, 30(2): 63-66. (In Chinese)

[5] Zhang F C, Lü, B, Zheng C L, et al. Microstructure of the worn surfaces of a bainitic steel railway crossing. Wear, 2010, 268 : 1243-1249.

[6] Zhang F C, Yang Z N, Kang J. Research progress of bainitic steel used for railway crossing. Journal of Yanshan University, 2013, 37(1): 1-7. (In Chinese)

[7] Cao D, Kang J, Long X Y, et al. Research on Heat Treatment of Bainitic Steel Crossing. Journal of Mechanical Engineering, 2014, 50: 47-52.

[8] Wang X, Zhang F C, Lü B, et al. Flash butt welding of bainite steel crossing with U71Mn steel rail. Transactions of the China Welding Institution, 2009, 30(12): 61-64. (In Chinese)

[9] Yang $Y Q$, Huang N X, Hu X Z. Microstructure and properties of electroslag casting bi-metal composite hammer head. Special Casting \& Nonferrous Alloys, 2010, 30: 751-753. (In Chinese)

[10] Zhang F C. Crossing steels and their hot working technologies. Beijing: China Machine Press, 2011: 183. (In Chinese)

[11] Li S, Cheng L. Technology research of resistance flashing welding for bainite alloy rail with PD3 rail. Electric Welding Machine, 2010, 40(1): 69-71. (In Chinese)

[12] Li C. Metallography Principle. Harbin: Harbin Institute of Technology Press, 1989: 211. (In Chinese) 